\title{
O discurso midiático por traz dos eventos: Cúpula dos Povos e Rio+20
} The media discourse behind the events: People's Summit and Rio +20

\author{
Dalvani Fernandes ${ }^{62}$ \\ Sileide France Turan Salvador
}

Artigo recebido em para publicação em fev/2013 e aceito para publicação em mai/2013

\section{Resumo}

O trabalho é impulsionado pelas seguintes questões: como foi o tratamento recebido pelos movimentos sociais hospedados no Sambódromo durante a Cúpula dos Povos em contraste com os líderes mundiais presentes na Rio+20? Como a mídia apresentou esse tema? Para abordar esse tema, trazemos como metodologia a Análise de Discurso, no contexto da interdição discursiva, chegando aos pressupostos da agregação e desagregação das distintas estratégias utilizadas pela mídia e pelo Estado. O objetivo principal desse ensaio é desenvolver uma reflexão sobre os discursos envolvendo a Cúpula dos Povos, produzindo assim, um registro de leitura do poder simbólico que envolve os grupos sociais.

Palavras-chave: Cúpula dos Povos. Rio+20. Poder Simbólico. Análise do Discurso.

\begin{abstract}
The work is boosted by the following questions: How was the treatment received by social movements hosted at Sambódromo during the Peoples Summit in contrast to the world leaders attending the Rio +20? How did the media show this theme? To address this issue, we present methodology as discourse analysis, in the context of discursive ban, reaching assumptions of aggregation and disaggregation of the different strategies used by the media and the state. The main objective of this paper is to develop a reflection on the discourses involving the People's Summit, thus producing a record of reading the symbolic power that involves social groups.
\end{abstract}

Keywords: People's Summit. Rio +20. Sustainability. Symbolic Power. Discourse Analysis.

\section{Introdução}

\author{
O canavial é a boca \\ Com que primeiro vão devorando \\ Matas capoeiras, \\ Pastos e cercados; \\ Com que devoram a terra \\ Onde um homem plantou seu roçado; \\ Depois os poucos metros \\ onde ele plantou sua casa; \\ depois o pouco espaço \\ de que precisa um homem sentado; \\ depois os sete palmos
}

\footnotetext{
62 Dalvani Fernandes: Possui graduação em Geografia pela Universidade Estadual do Centro-Oeste (2008), especialização em Educação e Gestão Ambiental pelo Instituto de Estudos Avançados e Pós-Graduação (2009) e mestrado em Geografia pela Universidade Federal do Paraná (2012). Atualmente é professor de Geografia do Instituto Federal de Educação, Ciência e Tecnologia do Paraná (Campus Curitiba) e doutorando em Geografia pela Universidade Federal do Paraná. E-mail: dalvani.fernandes@ifpr.edu.br (41) 8409-7911
}

Sileide France Turan Salvador: Mestre em Tecnologia, professora do Instituto Federal do Paraná - IFPR - Campus Curitiba Brasil. Possui Mestrado em Tecnologia pela Universidade Tecnológica Federal do Paraná, UTFPR (2010), Pós-Graduação em Especialização em Formação de Professores em EAD pela Universidade Federal do Paraná-UFPR (2001) e Graduação em Licenciatura em Letras Português - Inglês pela Universidade Tuiuti do Paraná-UTP (1998) pela Universidade Federal do Paraná. É professora do Instituto Federal de Educação, Ciência e Tecnologia do Paraná (Campus Curitiba), atuando no ensino de Língua Inglesa para o Ensino Médio. E-mail: sileide.salvador@ifpr.edu.br (41) 9138-7323 
onde ele vai ser enterrado

(MELO NETO, 1994, p.130)

Essa narrativa poética abarca os raciocínios imagéticos de uma metáfora pulsante e viva da relação existencial entre homem e natureza. Considerando o sentido semântico e metafórico das palavras, busca-se apresentar nas inter-relações do poema as representações da Cúpula dos Povos, da Rio+20, da sustentabilidade, da vida e da análise do discurso. O presente trabalho também busca um foco em contar nossa experiência da passagem pelo Sambódromo durante os dias do evento, bem como nossa vivência direta com membros dos mais diversos movimentos sociais brasileiros. Queremos com esse texto refletir sobre como as bases sociais articuladas politicamente foram tratadas na Cúpula dos Povos, em contraste com o glamour vivido pelos líderes mundiais que estavam presentes na Rio+20.

Vários estudos caracterizam a sociedade apresentada pela mídia como sociedade de espetáculo "subdividindo o conceito de espetáculo como expressão de uma situação histórica em que a mercadoria ocupou totalmente a vida social" (RUBIM, 2002, p.02). Nesse contexto o espetáculo, mercadoria e capitalismo estão interligados, sendo a Rio+20, uma extensão das práticas capitalistas. Para Pena (2004, p.88) "a espetacularização da vida toma o lugar das tradicionais formas de entretenimento". Portanto, a composição da notícia está impregnada da espetacularização e o espaço midiático consagra celebridades que catalisam os focos de atenção e ocupam o imaginário individual e coletivo, interferindo na forma que as populações veem e interpretam criticamente o mundo.

Refletir sobre os antagonismos presentes entre esses eventos paralelos, partindo da AD (Análise do Discurso), é uma maneira de observarmos as estratégias utilizadas pela grande mídia que revelam o seu interesse na manutenção de uma sociedade onde a informação aparece como entretenimento, contribuindo para que questões relevantes não tenham espaço em seus veículos de comunicação.

Por questões relevantes apresentamos o modo como foram tratados os participantes da Cúpula dos Povos que ficaram hospedados no Sambódromo do Rio de Janeiro. Escrevemos como observadores participantes que vivenciaram as condições precárias da estadia que, além da desorganização, contou com: falta de banheiros, médicos, colchões, marmitas estragadas, entre outras coisas.

\title{
A análise do discurso como ferramenta metodológica
}

\begin{abstract}
O sujeito linguístico é um sujeito de direito com sua ideologia que tem um efeito dentro de discurso. Sem a consideração da ideologia, se torna o sujeito como causa de si, não se levando em conta nem a história de sua constituição, nem a historicidade do sentido, pois não existe discurso sem sujeito e nem sujeito sem uma ideologia (SANTOS; MACEDO, 2010).
\end{abstract}

Baseada na Escola Francesa de Análise de Discurso, fundada por Michel Pêcheux (1938-1983), a metodologia deste estudo teoriza "como a linguagem é materializada na ideologia e como esta se manifesta na linguagem" (ORLANDI, 2005, p.10). Neste contexto, o Discurso ocupa um espaço particular no qual sua análise se estrutura por seu funcionamento, pelos mecanismos históricos e arranjos de significação, centraliza-se na inter-relação do simbólico e do político.

O Discurso, como categoria, possibilita a análise das relações de poder em significações e símbolos. Há espaços para ambiguidades, análise do imaginário, relações de sujeitos e linguagens. Importa conhecer as condições de produção do que é dito, ligando a literalidade da palavra, o mundo interior, a metáfora e o mundo exterior, estabelecendo uma transferência de significado. Assim, considera-se a criação discursiva como: estando exposto (...) "ao equívoco da língua: todo enunciado é intrinsecamente suscetível de tornar-se outro, diferente de si mesmo, se deslocar discursivamente de seu sentido para derivar para outro" (PECHÊUX, 1983, p.53).

O silêncio também é um discurso. Nos inquieta o silêncio da grande mídia sobre os acontecimentos que relataremos a seguir. Citamos fonte da internet, pois quase nada foi registrado pela TV aberta. A massa do povo brasileiro, que como bem sabemos, em sua grande maioria se informa pelos jornais televisivos, não ficou sabendo do descaso que as pessoas foram tratadas nos alojamentos da Cúpula dos Povos. O silêncio da grande mídia demonstra aquilo que Foucault (2006), chama de interdição discursiva. Essas interdições revelam a ligação com o desejo e com o poder (proibição de se falar sobre determinado assunto). Se as pessoas falam algo que não se encaixa no discurso, a instituição pode acusar esse contra discurso de loucura. Para Foucault, a fala não é livre. Há aqueles que podem falar (que são instituídos para isso), e há também aqueles que têm seus discursos interditados. Algumas instituições decidem quem e quando se fala, como se fala, o que se fala. 
Esse fenômeno revela a vontade de verdade, outro conceito foucaultiano, ele seria um mecanismo de controle dos discursos. Um desejo de que, aquilo que se diz, seja verdade. $\mathrm{O}$ ato de dizer, quando legitimado por uma instituição ganha contornos de verdade. Nessa linha de raciocínio, o silêncio da grande mídia indica que as coisas vão bem, que não houveram problemas nos alojamentos, que todas as pessoas estavam em ótimas condições. Foucault (2006), nos alerta que o argumento defendido pela instituição não é necessariamente verdadeiro, ele é apropriado por outros mais pelo poder de quem fala (Rede Globo, por exemplo) do que pela veracidade dos argumentos. Sendo assim, o discurso é convertido em verdade, ou melhor, ganha contornos de verdade.

Bourdieu (1996) e Foucault (2006), demonstram que a linguagem é inseparável da instituição. Todo discurso pressupõe uma ordem, e essa ordem é imposta pela instituição. Isso, pois, o discurso é muito mais que um simples dizer - ele é poder:

[...]o discurso - como a psicanálise nos mostrou - não é simplesmente aquilo que manifesta (ou oculta) o desejo; é, também, aquilo que é o objeto do desejo; e visto que isto a história não cessa de nos ensinar - o discurso não é simplesmente aquilo que traduz as lutas ou os sistemas de dominação, mas aquilo por que, pelo que se luta, o poder do qual nos queremos apoderar. (FOUCAULT, 2006, p.10)

As interrogações que ficam no ar são: o que esse silêncio significa? E, a quem serve esse poder? Tentamos no final desse texto apresentar alguns caminhos que nos ajudem a encontrarmos respostas para essa questão.

Subjetividades como: cor das imagens, intertextualidade, formas de organização e hierarquização das informações, são, através da composição do espetáculo e do discurso; elementos que concretizam o sentido de um evento histórico, a consolidação do imaginário social. A mídia oferta uma interpretação do mundo, "não a realidade, mas uma construção que permite ao leitor produzir formas simbólicas de representação da sua relação com a realidade concreta" (GERGOLIN, 203, p.97).

O maior objetivo desse trabalho, além da reflexão sobre os discursos envolvendo a Cúpula dos Povos, é produzir um registro que sirva como poder simbólico para os grupos sociais, tendo em vista que,

(...) o poder simbólico permite exprimir o sofrimento, a decepção, a alegria, todos os sentimentos associados aos tempos fortes do ciclo de vida de um grupo social e, num outro registro, veicular os anseios, as expectativas, as identidades e demais sinalizações pertinentes com que os grupos sociais buscam afirmar sua diferença por meio dos encantamentos instilados em sua definição dos mistérios da vida e do mundo. (BOURDIEU, 1996, p.14).

\title{
A Cúpula dos Povos: retrato do Brasil
}

\author{
"Esse Brasil lindo e trigueiro \\ É o meu Brasil Brasileiro \\ Terra de samba e pandeiro..." \\ (Aquarela do Brasil, João Gillberto)
}

A Cúpula dos Povos foi inspirada no Fórum Global, também realizado no Rio de Janeiro conhecido mundialmente como "Rio 92" - realizado também no Aterro do Flamengo. De acordo com informações da $\mathrm{BBC}^{63}$, para o ano de 2012, 15 mil ativistas foram esperados para a cidade do Rio de Janeiro para participar da Cúpula dos Povos. Essas pessoas ficaram em alojamentos distribuídos pela cidade, entre eles o Sambódromo, escolas públicas e a Universidade Federal do Rio de Janeiro.

Somente no Sambódromo, cerca de 7.900 pessoas ficaram instaladas no decorrer dos dez dias do evento. A entrada da imprensa no Sambódromo foi proibida. Em reportagem exibida no portal "terra.com.br" encontramos o seguinte relato: "Não se pode entrar, isso agora é propriedade privada", explica Edson Souza, um voluntário que diz cumprir ordens dos organizadores. "A comodidade é mínima e não há nada para comer", queixa-se Antonio Regivaldo, 32 anos, da União Popular por uma Moradia. $\mathrm{Na}$ sequência do texto do referido sítio virtual, encontramos o relato de Sandro Potiguara, cacique da

\footnotetext{
${ }^{63}$ Informação disponível no sítio: http://www.bbc.co.uk/portuguese/noticias/2012/06/120615 cupula povos jc.shtml Acessado em: 27/06/2012.
} 
tribo Potiguara, dizendo que: "Está mal organizado. Deveriam nos dar café da manhã, mas, como sempre, os que têm menos são esquecido" ${ }^{\circ 4}$.

A Cúpula dos Povos foi realizada por iniciativa de 200 organizações ambientalistas e movimentos sociais do mundo inteiro, para, principalmente, lutar contra o mercantilismo e defender os bens comuns. O governo brasileiro foi seu maior financiador, contribuindo com 5 milhões de dólares, aponta jornal "O Povo" 65

Em reportagem exibida no portal virtual G1, no dia 13 de junho de 2012, houve a notícia de que cerca de 10 mil pessoas deveriam ficar instaladas no Sambódromo do Centro do Rio de Janeiro, e nesse espaço haviam mais de 200 banheiros químicos instalados ${ }^{66}$. Pensemos como os organizadores, 10.000 pessoas para utilizar 200 banheiros. Seriam 50 pessoas por banheiro! Qual a higiene de um banheiro desses? Quantas vezes ele deveria ser limpo por dia para atender minimamente as pessoas? Houve preocupação com a salubridade do espaço, houve preocupação com as seres humanos, e principalmente, com a vida?

O relato denúncia trazido pela reportagem do Estadão, traz as impressões de algumas pessoas que ficaram alojadas no Sambódromo durante a Cúpula dos Povos:

\begin{abstract}
As principais queixas daqueles que ficaram no Sambódromo dizem respeito às péssimas condições de higiene do local e à comida, que estava estragada e fez com que alguns passassem mal. "Nunca vi tanto desrespeito. Eles trouxeram índios para virarem atração turística. Não tiveram a menor dignidade ao tratar os povos tradicionais", reclamou a educadora paulista Mirian Orensztejn, que estava com a neta, a índia carajá Myralu Werreria Orensztejn, de 3 anos.

A organização não se responsabiliza pela alimentação comprada. "Alguns grupos receberam vale-refeição e uma lista de restaurantes credenciados. Mas preferiram comprar em locais não recomendados", disse Alessandra Alli, coordenadora de alojamento da Cúpula dos Povos ${ }^{67}$.
\end{abstract}

Como podemos observar na reportagem acima, os responsáveis pelos alojamentos colocam a culpa nas pessoas que, segundo eles, irresponsavelmente não compraram nos lugares recomendados, assumindo assim os riscos pela escolha. Quanto a isso, cabe uma ressalva. Estivemos presentes no evento durante os dias 16 a 21 de junho, também instalados no Sambódromo, e não recebemos nenhuma lista de restaurantes credenciados. Também não recebemos vale-refeição (tíquetes) todos os dias em que estivemos no Sambódromo. Esse fato nos leva as contas mais uma vez; segundo a estimativa, seriam 10 mil pessoas recebendo 24 reais de vale-refeição por dia, durante 10 dias, temos um gasto total de $R$ \$ 2,4 milhões (somente no Sambódromo!). Levando em consideração que o Governo Federal destinou 5 milhões de dólares fica a questão - por que as pessoas não receberam tickets todos os dias? O que foi feito com esses vales-refeições que não foram entregues? Quem são os líderes responsáveis por repassar esse valor à população que estava alojada no Sambódromo? A quem cabe repassar uma prestação de contas à população?

Diante do descaso e abandono das pessoas que participam da Cúpula dos Povos, cabe registrar as palavras publicadas pelo Jornal Correio do Estado, que demonstrou a indignação do Povo Indígena da etnia Yanomami. O índio Kopenão, de Roraima, disse que ficou indignado ao receber a marmita com alimentos estragados. Em suas palavras: "Não é comida para cachorro, é comida contaminada que se dá para os indígenas", reclamou. "Somos seres humanos. Nem animal comia aquilo". Segundo ele, a carne estava ruim e dava para sentir o cheiro ao abrir a quentinha ${ }^{68}$.

Participante da Cúpula dos Povos ilustra com suas palavras como o povo brasileiro está acostumado a ser tratado; sempre recebendo o mínimo (salário mínimo, educação mínima, saúde

\footnotetext{
64 Informação disponível no vídeo encontrado no sítio: http://noticias.terra.com.br/brasil/noticias/0,,015840711-El306,00Sambodromo+se+transforma+em+camping+para+ativistas+e+indigenas.html Acessado em: 27/06/2012.

65 Informação disponível no sítio: http://www.opovo.com.br/app/maisnoticias/brasil/2012/06/12/noticiasbrasil,2857419/afp-cupulados-povos-no-rio-espaco-para-o-descontentamento-da-socie.shtml Acessado em: 27/06/2012.

66 Informação disponível no sítio: http://g1.globo.com/natureza/rio20/noticia/2012/06/sambodromo-vira-alojamento-paraparticipantes-da-cupula-dos-povos.html Acessado em: 27/06/2012.

Informação disponível no sítio: http://estadao.br.msn.com/ciencia/participantes-da-c\%C3\%BApula-dos-povos-sofreram-comestrutura Acessado em: 27/06/2012.

${ }^{68}$ Informação disponível no sítio: http://www.correiodoestado.com.br/noticias/indios-recebem-comida-estragada-durante-cupula-dospovos 152287/ Acessado em: 27/06/2012.
} 
mínima, respeito mínimo, etc.) e, mesmo assim, agradecendo. Ao ser questionado sobre as condições das instalações em que ficou alojado no Rio de Janeiro, o participante responde: "Não ta ótimo, mas pelo menos a gente tem um lugar onde a gente pode tirar um colchão, e dormir" ${ }^{\prime 69}$. Grande contraste com os hotéis luxuosos que serviram de morada para os líderes mundiais e convidados especiais na Rio+20. 0 relato de pessoas que, apesar de terem sofrido com o cansaço e com as acomodações precárias, dizem saírem da Cúpula dos Povos satisfeitos ${ }^{70}$ não são difíceis de encontrar. O povo, acostumado com 0 sofrimento, teve a capacidade de manter a cabeça erguida e aproveitar os pontos fortes do evento, como os espaços de diálogos, cursos, palestras e manifestações pacíficas.

O "bode expiatório", para todos os problemas enfrentados no Sambódromo, foi apontado pelos organizadores como sendo o povo Indígena. Conforme expressa o texto abaixo retirado do site "terra.com.br":

\begin{abstract}
Membro da comissão de Direitos Humanos da OAB-RJ, e defensor dos direitos indígenas no Rio, o advogado Arão da Providência Araújo também constatou o problema, e foi outro que não conseguiu se alimentar. "Ninguém comeu direito hoje aqui, deram uns tíquetes para gente, mas eles não são aceitos aqui, teríamos que comer fora da Cúpula", explicou. A responsabilidade da Cúpula é prover um tíquete alimentação no valor diário de $R \$ 24$ a cada um dos 15 mil participantes "para que eles possam se alimentar antes ou depois de estarem aqui, além de água, e alojamentos. Conversamos com os líderes e demos alguns tíquetes a mais para eles se alimentarem, mas o principal problema dessa questão foi que eles passaram um número de 1.100 índios no evento e vieram muito mais do que isso", ponderou a diretora.

O excesso de contingente indígena prejudicou também as instalações no sambódromo, local de alojamento dos índios, no centro do Rio. Indígenas, que não quiseram se identificar temendo algum tipo de represália das lideranças, afirmaram para a reportagem que não existem colchões para todos, que muitos estão dormindo no chão ${ }^{71}$.
\end{abstract}

Enquanto alguns setores da mídia noticiavam as péssimas condições de acomodação das milhares de pessoas no Sambódromo, outras fontes, no entanto, utilizam suas páginas para divulgar temas que consideram mais pertinente, à exemplo da reportagem exibida no dia 21 de junho de 2012 pelo portal G1 da Globo : "De patricinhas a hippie, Cúpula dos Povos tem musas de todos os estilos" - 0 texto trata das jovens que atraem flashes no evento, "para driblar o calor, meninas apostam no short jeans para compor look", expõe o elucidativo texto.

\title{
Rio+20 e Cúpula dos Povos - reflexões sobre a política no Brasil
}

Nossa exposição anterior, partindo do que foi noticiado pela mídia virtual, nos provoca a fazermos uma breve reflexão sobre esse encontro fantástico que foi a Rio+20 e a Cúpula do Povos. Talvez seja consenso entre aqueles que acompanharam de perto esses dois eventos em 2012 que ambos foram a expressão do Zeigst que vivemos. De um lado os poderosos líderes mundiais representando os interesses de uma elite global, a Rio+20 foi a expressão de como as coisas podem ser organizadas quanto o que está em jogo é a imagem do país.

Por outro lado temos a Cúpula dos Povos que demonstraram a força dos movimentos de base no país e no mundo. As passeatas, reuniões, palestras, abriram espaço para o povo gritar seu descontentamento por um modo de vida que prejudica o mundo e a humanidade. Também podemos observar a fragmentação dos interesses populares, muitos grupos erguendo diferentes bandeiras: anarquistas, feministas, movimento sem terra, movimento sem teto, movimento indígena, movimento por moradia popular, movimento quilombola, para citar alguns.

\footnotetext{
69 Informação disponível no vídeo encontrado no sítio: http://g1.globo.com/natureza/rio20/noticia/2012/06/g1-promove-encontroinusitado-na-cupula-dos-povos-da-rio20.html Acessado em: 27/06/2012.

70 Informação disponível no sítio: http://www.jb.com.br/ambiental/noticias/2012/06/22/participantes-da-cupula-dos-povos-voltampara-casa-levando-novas-experiencias/ Acessado em: 27/06/2012.

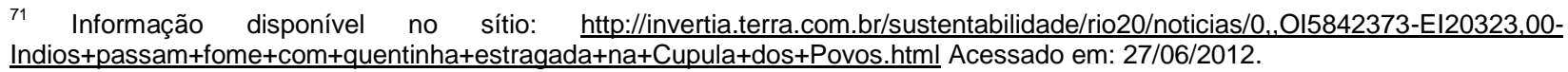


A declaração final da Cúpula dos Povos na Rio+20 foi divulgada na internet ${ }^{72}$, com o título: "Por Justiça Social e Ambiental em Defesa dos Bens Comuns, Contra a Mercantilização da Vida". No documento em questão, encontramos um texto preocupado em atacar o atual mercado financeiro, a sociedade de consumo e, principalmente a mercantilização da vida - seja, humana, animal ou vegetal.

Interessante notarmos, que apesar das intenções, o que vivemos e experienciamos foi totalmente o contrário da luta contra a mercantilização da vida. Durante os dias da Cúpula dos Povos, observamos pessoas passando fome no Sambódromo, pessoas dormindo em jornais, tíquetes que simplesmente desapareceram. Pudemos observar o que há de pior na política brasileira sendo reproduzida da maneira mais fria e cruel. Se as pessoas participassem das barracas e palestras definidas pelo líder de determinado grupo, elas ganhariam o direito a alimentação. Se as pessoas não "obedecessem" seus líderes os vales-refeições não eram recebidos. Uma troca desumana, desigual, injusta: o apoio popular pelo pão. Isso nos lembra um pouco como as coisas que acontecem em macro escala, nível Brasil, se reproduzem em micro escala, nível local do Sambódromo. Nos parece que os líderes populares estão aprendendo com nossos representantes corruptos.

A democracia, mais uma vez, foi esquecida de ser convidada para ambos os eventos. Na Rio+20 o que imperou foi o interesse dos detentores do capital. Na Cúpula dos Povos, apesar das boas intenções, nos parece que o discurso não conseguir chegar as bases e se tornar algo real, preocupado com o ser humano e com a valorização da vida.

\section{Considerações Finais}

A Rio+20, arena de discussão que buscou o consenso sobre a construção de uma sociedade ecologicamente equilibrada e atuante, agrupou, em suas múltiplas formas de representação os mais diversos embates e visões de mundo. Conjugando, sob o mesmo teto diversos projetos de sociedade, alguns semelhantes, outros conflitantes, e até mesmo antagônicos. Essa estrutura favoreceu não um discurso sustentável unívoco, mas um discurso plural, passível de ser analisado, permitindo uma visão holística do que representou esse evento histórico.

Se para Leis (1998) os dois problemas básicos que fomentam, agregam e desagregam as distintas estratégias de sustentabilidade estão na reflexão das questões ambientais, partindo da relação entre ser humano e a natureza, bem como na relação entre ser humano e a sociedade, pode-se analisar que a Rio+20 desvalorizou os aspectos antropocêntricos desses discursos, valorando os discursos biocêntricos, de unidade e integração (JUNGES, 2004). Portanto, o evento priorizou a coletividade, e, se, pelos jornais de grande circulação - gerenciados por grandes grupos econômicos -, percebeu-se a maior visibilidade de certos grupos representados, outros instrumentos midiáticos - veiculados pela mídia digital -, de certa forma, demonstraram que os indivíduos e grupos menos favorecidos buscaram visibilidade e voz. Consolidaram-se os emergentes desafios conjugados nos termos como "degradação", "esgotamento" e "extinção", especificados nos discursos sobre recursos naturais, espécies de fauna e flora, meio ambiente e desenvolvimento sustentável.

Por isso, ao explanar sobre a importância da análise do discurso do texto jornalístico da Rio+20, importa considerar não só os aspectos comunicativos, mas também a intenção, descrever o momento histórico, teorizar e conceituar essa análise do discurso, clarificando-a em suas principais características, eficácia de transmissão da mensagem, forma e ideologias. Assim, vale diferenciar os múltiplos objetivos do discurso, quando as premissas integram um arcabouço de comunicação política, os pressupostos do marketing político, as teorias e ideologias. Todos envoltos no contexto de um momento histórico específico, para um público certo, com forte aspecto de representação de imagem de movimentos, nações, atores/atrizes políticos, em seu sucesso ou fracasso da imagem pública.

Ao analisar esses discursos, lê-se uma comunicação não condensável, sem fórmulas exatas e imutáveis. A Rio+20 pode ser registrada como evolutiva e dinâmica em seus processos, e se promoveu a convergência de áreas do conhecimento, diluiu-se nos modos de procedimentos e na utilização das aplicações das soluções nos mais notórios diversos níveis de estabelecimento da relação política com a sociedade.

No contexto da propaganda, o megaevento em questão seguiu uma estética com planejamentos estratégicos, estudos e pesquisas que confundiram ciência com publicidade e propaganda, pois buscou

\footnotetext{
72 Informação disponível no sítio: http://cupuladospovos.org.br/wp-content/uploads/2012/06/Carta-final Cupula-dos-Povos.pdf Acessado em: 27/06/2012.
} 
criar, e transformar as opiniões, através dos mais diversos meios explicitando objetivos científicos, comerciais e políticos. Se o conteúdo jornalístico pretendeu suscitar preferências, também visou estimular necessidades e sugerir reflexões e crenças, moldando e forjando modificações de ideologias convicções científicas, religiosas e a manipulação de comportamentos. A análise do discurso demonstra que o jornal, como categoria, age sobre o psiquismo o mesmo tempo indo além e, por suas características de propaganda, influenciando em atitudes fundamentais, convencendo, subjugando, amoldando.

Para os autores desse trabalho, o discurso pode ser analisado enquanto conteúdo não só em seu sentido, mas também em seu funcionamento, nas complexidades de suas subjetividades ideológicas, econômicas, políticas e sociais. Assim, lê-se o que foi dito, o que não foi dito, o contexto que envolveu 0 discurso, os objetivos e as metáforas. O discurso jornalístico da Rio+20 otimizou a relação de poder e construiu sistemas de representação, problematizou sujeitos e ideologias (ORLANDI, 1998). Propiciou o fenômeno da interação, reificando o poder através da divulgação de documentos e ações.

A Cúpula dos Povos representou a união dos movimentos populares: índios, negros, sem-teto, sem-terra, estudantes, entre tantos outros grupos organizados, que em comum tem a pobreza. A maneira como eles foram tratados no Rio de Janeiro deixou claro que o apartheid social (BUARQUE, 1999) em nosso país é uma dura realidade. A diferença que os brasileiros economicamente privilegiados assumem em relação aos pobres revela mecanismos de separação; mecanismos estes que calam a voz do povo, e que maquiam a realidade. A manipulação do discurso midiático é um instrumento que possibilita a manutenção do poder, dos "contornos da verdade", pois facilita ou dificulta o que a massa da população pode/deve saber.

Buarque (1999, p.48) coloca como um dos exemplos mais trágicos da apartação social no Brasil, "a forma como os intelectuais se isolaram do povo reduziram seus compromissos libertários e caíram na burocracia do trabalho acadêmico", ora, se os próprios acadêmicos se colocam a margem desse debate, o que esperar de um jornalismo vinculado aos interesses econômicos de um grupo minoritário?

O silêncio da grande mídia revela um paradoxo, pois a Rio+20 foi um evento voltado para discutir questões como a crise ambiental, isto é, despertar na humanidade a consciência de que estamos no "mesmo barco", a humanidade é uma só e precisa compartilhar esse planeta. No entanto, a divisão entre os interesses representados pela Cúpula dos Povos e a Rio+20 mostraram justamente o contrário. A maneira como os participantes desses eventos foram tratados, os espaços que tiveram na mídia e os resultados que obtiveram em seus respectivos encontros nos leva a crer que há muito ainda a se fazer para que haja uma unidade entre os diferentes grupos humanos.

\section{Referências}

BOURDIEU, P. Economia das Trocas Linguísticas: o que falar quer dizer. São Paulo: EDUSP, 1996.

BUARQUE, C. O que é apartação: o apartheid social no Brasil. São Paulo: Brasiliense, 1999.

DOMENACH, J. M. La propagande politique. Série "Que sais-je"? 448, Paris: Presses Universitaires de France, 1950.

FOUCAULT, M. A Ordem do Discurso. 13르d. São Paulo. Loyola. 2006.

GREGOLIN, M. do R. O acontecimento discursivo na mídia: metáfora de uma breve história do tempo. In: GREGOLIN, Maria do Rosário (org.). Discurso e mídia: a altura do espetáculo. São Carlos: Claraluz Editora, 2003.

JUNGES, J. R. Ética Ambiental. São Leopoldo: Unisinos, 2004.

LEIS, H. R. Ambientalismo: um projeto realista-utópico para a política mundial. In: VIOLA, E. J. et al. Meio Ambiente, Desenvolvimento e Cidadania: desafios para as ciências sociais. 2a ${ }^{\text {a }}$ Edição. São Paulo: Cortez/Florianópolis, UFSC, 1998.

MELO NETO, João Cabral. Obra Completa. Rio de Janeiro: Editora Nova Aguilar S.A., 1994. 
ORLANDI, E. P. Michel Pêcheux e a Análise de Discurso. Estudos da Lingua(gem). n 1. Vitória da Conquista, junho/2005, p. 9-13.

PÊCHEUX, M. O discurso: estrutura ou acontecimento. Trad. Eni Pulcinelli Orlandi. Campinas: Pontes, 1997. Edição original: 1983.

PENA, F. Teoria do Jornalismo. São Paulo: Contexto, 205.

RUBIM, A. A. C. Espetáculo, política e mídia. Disponível em: http://www.bocc.uff.br/pag/rubim-antonioespetaculo-politica.pdf.Acesso em: jan. 2013.

SANTOS, K. R. G.; MACEDO, R. G. A Importância da Análise do Discurso na Comunicação Política: UFRN, 2010.

TORQUATO, F. G. R. Marketing Político e Governamental. São Paulo: Summus, 1985. 